\title{
Temporal Dynamic Analysis of Land-use Change and its Economic Evaluation During a 21-year Period in a Diverse Land-use Configuration
}

Hossein Talebi Khiavi

Tarbiat Modares University

Seyyede Khamsa Asbaghian Namini

Tarbiat Modares University

Mohammad Ali Asaadi

Tarbiat Modares University

Raoof Mostafazadeh ( $\nabla$ raoofmostafazadeh@uma.ac.ir)

Faculty of Agriculture and Natural Resources, University of Mohaghegh Ardabili https://orcid.org/00000002-0401-0260

\section{Research Article}

Keywords: Land use change dynamics, Economic evaluation, Change matrix, East Meshgin, Ardabil, Iran

Posted Date: June 14th, 2021

DOl: https://doi.org/10.21203/rs.3.rs-506852/v1

License: (c) (i) This work is licensed under a Creative Commons Attribution 4.0 International License.

Read Full License 


\title{
Temporal dynamic analysis of land-use change and its economic evaluation during a 21-year period in a diverse land-use configuration
}

\author{
Hossein Talebi Khiavi' ${ }^{1}$, Seyyede Khamsa Asbaghian Namini², Mohammad Ali Asaadi ${ }^{3}$, and \\ Raoof Mostafazadeh ${ }^{4}$ \\ ${ }^{1}$ M.Sc. in Soil Science, Department of Soil Science and Engineering, Tarbiat Modares University, Iran \\ ${ }^{2}$ M.Sc. student of Soil Science, Department of Soil Science and Engineering, Tarbiat Modares University, \\ Iran \\ ${ }^{3}$ M.Sc. student of Agricultural Economic, Department of Agricultural Economic, Tarbiat Modares \\ University, Iran \\ ${ }^{4}$ Associate Professor and Member of Water Management Research Center, Department of Natural \\ Resources, Faculty of Agriculture and Natural Resources, University of Mohaghegh Ardabili, Iran \\ (Corresponding Author Email: raoofmostafazadeh@uma.ac.ir, Tel: +989144815743)
}

\begin{abstract}
Investigating the rate and the process of land-use change and its economic effects during the last years are among the main bases of land management in the future. East Meshgin region in Ardabil province is one of the agricultural production centers, where the construction of the Sabalan dam developed the agricultural activities. In this research, the six land uses, including rangeland, orchard, agriculture, bare land, outcrop, and water bodies during the years of 1998-1999, were classified using Landsat imagery. Also, the single and comprehensive dynamic land-use change indices were employed to compute the rate and process of land-use change. The land-use change matrix is developed in three time periods (1998-2003, 2003-2008, and 2013-2019). The economic evaluation of land use has been conducted during this period. The results showed that the highest rate of land-use change was converting the rangeland to bare lands. While in the period of 20082013, the highest rate of land-use change was rangeland conversion to agriculture lands that has caused increased net income by $4027,258 \$$. The collected data relates to the total period also confirms the change of rangeland use to bare lands. Also, the results of the single dynamic landuse change model show that in each period, the most change was related to water body land use. Among other land-uses, the highest rate of change was related to agricultural land use between 2013-2019 in the period of Sabalan dam operation. This study is performed to facilitate policymakers, planners, and other development stakeholders in this sector to adopt the best option for land-use management and sustainable land development.
\end{abstract}

Keywords: Land use change dynamics, Economic evaluation, Change matrix, East Meshgin, Ardabil, Iran.

\section{Introduction}

Land use/land cover change (LULC) is a key basis for the study of natural resource management, climate change (Lambin et al., 2003; Y Tasai et al., 2015) and urban planning (Li et al., 2016) as well as one of the most important factors in environmental assessment, as a vital tool for assessing global change in spatial-temporal scales (Lambin, 1997). The effects of LULC on the sustainability of ecosystems have become a considerable issue in research on global change (Kamural Islam et al., 2018). With the intensification of various global issues such as population growth, food shortages environmental pollution, and climate change, global change has become one of the most attractive fields of research in which land-use change is very momentous (Zeng et al., 2008; Aspinall, 2004). Land use is an important factor that has been affected by human uses for economic 
and social expansion. Therefore, it is manipulated by human activities in terms of the structure and process of the environment (Hamad et al., 2018). Land-use change is the outcome of human use, economic income, and ecological process interactions (He et al., 2008). Therefore, human beings and human activities are the constituent factors of land-use change. As a result, land-use change is one of the inevitable processes and is the product of the trade-off between human and natural factors.

Land-use change is a dynamic and continuous process (Mondal et al., 2016), which its information can play a vital role in natural resource management (Lin et al., 2015). Quantitative measurement of spatial land-use patterns and land-use change is important to understand regional land evolution and environmental security (Shuhan Liu et al., 2017). Acceptable accuracy in detecting land dynamics changes can provide basic data for research on human-nature interactions (Gautam et al., 1985; Sen et al., 2015). The land-use change matrix is an important method for describing and measuring land-use change and can show the trend of different types of land use (Wen Sun et al., 2012). Numerous techniques are available for the diagnosis and evaluation of LULC change, among which the remote sensing method and the GIS technique have been widely used by researchers in the field of LULC studies. Remote sensing techniques have been recognized as a powerful tool for obtaining information on the surface characteristics of the earth (Satyanarayana et al., 2001) at specific spatial and temporal scales (Liang et al., 2015).

Many researchers have studied methods for monitoring land use/cover changes using satellite imagery and remote sensing techniques. Yafei Le et al. (2017) have investigated the dynamics of land-use change in the Jing-Jin-Ji region of China between 2000 and 2015 using the equation of single land-use dynamics and comprehensive land-use dynamics. According to their results, the highest degree of single land-use dynamics was related to bare lands, and the main feature of dynamic land-use change in the study area is the rapid decline of agricultural lands and the sharp growth of urban lands. Shuhan et al. (2017) had shown human activities and the impacts that caused ecological land reduction and transformed these lands into other land use classes between 1996 and 2014 in the Nong'an area. Their findings illustrate that the change between these lands, agricultural lands, and residential lands is constantly occurring, and human activity is an important factor that has an impact on land use patterns. An increasing trend in urban and agricultural lands has been reported by Amini Parsa et al. (2016) in the Naghadeh region of East Azerbaijan in Iran from 1989 to 2014. The consequent decrease of bare lands has been quite evident in their results. According to their statement, if the management process continues in the same way, the reduction of resources and irrigated and bare lands are guaranteed until 2041. This trend in this region, as part of Urmia Lake, will have significant impacts on the environment, natural resources, ecosystems, specifically on Urmia Lake and human habitation (Anvari \& Valaie, 2015).

In a study by Othow et al. (2017), which aimed to investigate land use/land cover change in Ethiopia, a gradual increase in agricultural lands from 4\% in 2002 to $23 \%$ in 2017 has been determined. Also, a decrease in forest cover from 23\% in 2002 to 18/11\% in 2017 was reported, which is due to economic exploitation and, as a result, being converted to agricultural lands. The other reasons for forest encroachment were forest fires, population growth, deforestation, coal and fuel extraction, and poor management of natural resources in the region that had caused soil erosion, reducing soil fertility and fauna migration. Kamrul Islam et al. (2018) had studied the regional land-use change in Bangladesh between 2000 and 2015 by using Landsat satellite imagery and supervised classification of maximum likelihood. According to the results of their study, it was found that about 256 hectares of the destroyed forest area have increased during these ten 
years, an annual rate of 25.56 percent. In another study in Bangladesh, Md Abdollah et al. (2019) concluded that in coastal areas, there is a 5.44\% increase in agricultural lands, and areas with vegetation have a significant decrease during the 2017-2019 years due to human impacts. A study by Khawaldah et al. (2020) based on modeling and forecasting approach of land use and vegetation cover changes using the Markov cellular automata model in Jordan had shown a significant increase in urbanization during the period under review in 1984, 1994, 2004, and 2015. According to that study, a trend is expected to increase by 2031, which is mainly due to population growth and socio-economic changes. In addition to the above, many studies have been conducted in the field of land-use dynamics assessment (De Fries et al. (2010); Zhang et al. (2011); AlRazzaq Abd and Alnajjar (2013); Sujatha et al. (2014); Butt et al. (2015); Meshesha et al. (2016); Xiangmei et al. (2016)).

Iran is a rich country in terms of agriculture, and the main occupation of its most villagers is agriculture and animal husbandry. East Meshgin region has become one of the agricultural production centers of Ardabil province due to the considerable extent of agricultural lands and the availability of water because of Sabalan dam construction and operation. This area has experienced a significant change in land use from the past till now. In the present study, land-use change data from 1998 to 2019 were extracted using remote sensing techniques and satellite imagery. Therefore, the main aim of the current research is to apply single and comprehensive dynamic change indices to determine the rate and process of land-use changes over the study area. In the next step, the economic impacts of land-use change have been evaluated and quantified to estimate the quantitative financial consequence of land-use change.

\section{Methodology}

\subsection{Study area}

East Meshgin region, with an area of 2611 square kilometers in the central part of Ardabil province, is located at $47^{\circ} 27^{\prime}$ to $48^{\circ} 16^{\prime}$ east longitude and $38^{\circ} 15^{\prime}$ to $38^{\circ} 55^{\prime}$ north latitude. Based on the modified Damarten subdivision, the area has a cold semi-arid climate. The length of dry and semiarid and frosty spells is five to eight months, and the average annual rainfall is $300 \mathrm{~mm}$. The location of the study area in Ardabil and Iran has shown in Figure 1. 


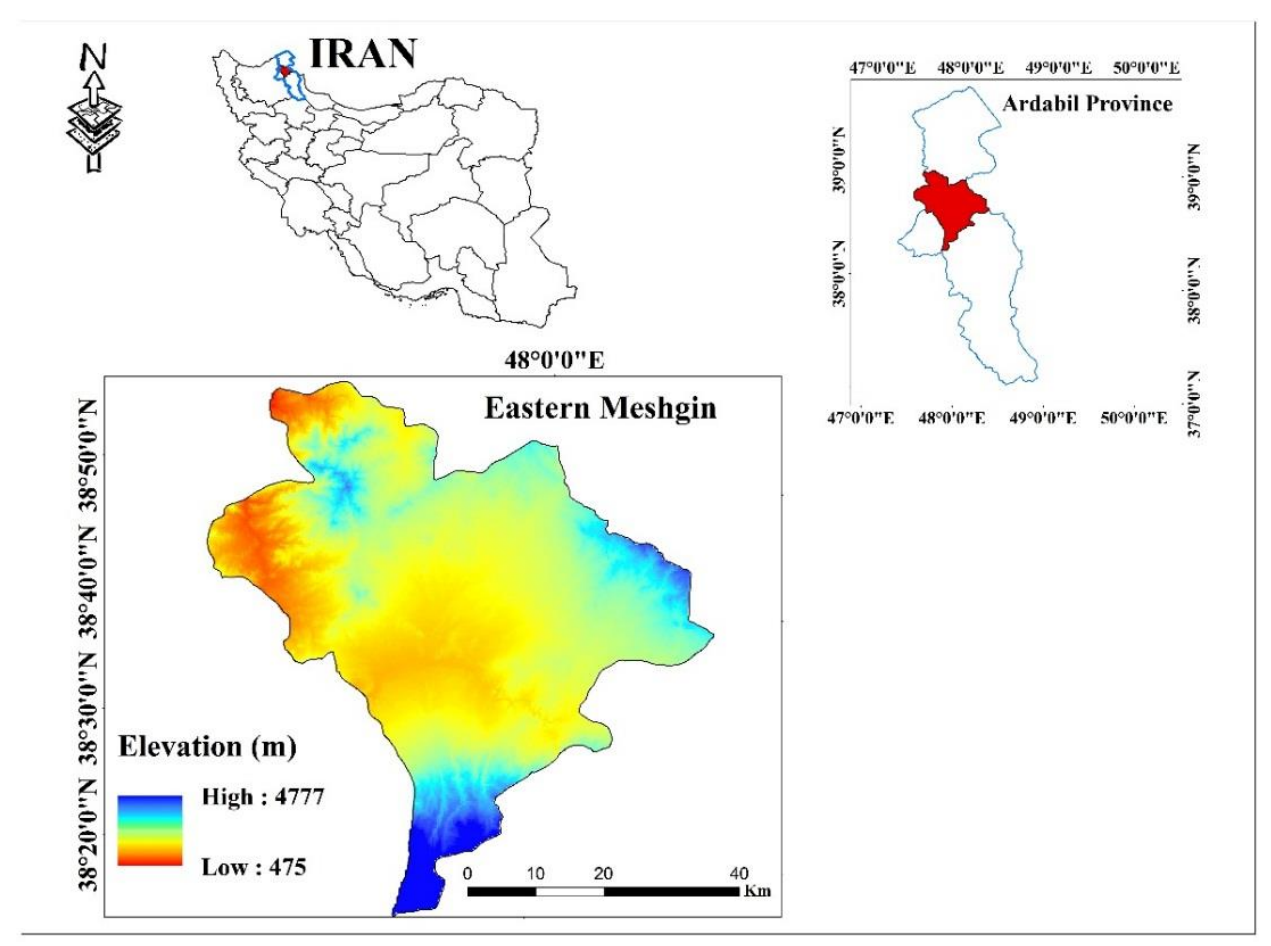

Figure 1: The location of the study area in Ardabil province

\subsection{Data collection methods}

The Landsat satellite imagery was obtained from the US Geological Survey's Natural Resources Observation Terminal Database website. The satellite images were chosen based on the geographical coordinate system (UTM) of the study area in WGS1984 and 39-North zone extent. The satellite images were prepared for the pre-processing procedure by ENVI 5.3 software. Atmospheric correction was performed using the Quick atmospheric method, and all images were co-registered with the images related to 2018. Then, to improve the quality of the classification of different vegetation covers, the 30-meter Aster DEM image has been added to the relevant datasets each year. Due to the fact that the topographic effect can cause significant errors in the classification of images, especially in areas with high protrusions (Gilabert et al., 1993; Fahsi, 1993; Civco, 1989), the effect of digital elevation models (DEMs) in reducing this effect and improving image classification has been demonstrated (Fahsi et al., 2000). Fahsi et al. (2000) had shown that DEM data improve classification accuracy by reducing the effect of ups and downs on satellite images. Also, the coefficient of variation (standard deviation divided by the mean) for areas with homogeneous coverage is significantly reduced for all spectral bands in the image correction procedure. Therefore, the overall accuracy and kappa coefficient are significantly improved.

\subsection{Image classification}

Several factors must be considered in choosing the classification method, including the spatial resolution of satellite imagery, the different data sources, the classification system, and the availability of the classification software. The answer to the question of whether the classification method is appropriate for a particular study is not an easy task. Depending on the employed classification technique, the obtained classification results may be different (Lu and Weng, 2007). 
Six evaluation criteria have been proposed by Cihlar et al. (1998) to evaluate the performance of a classification method, which includes accuracy, reproducibility, robustness, ability to use all the data information content, uniform application, and objectivity. In fact, due to the difference in environmental conditions and the data used, no classification algorithm can meet all these requirements and applicable to all studies (Lu and Weng, 2007). The Maximum Likelihood method is one of the most widely used supervised classification methods (Pal et al., 2003; Mariame Mohajane et al., 2018). The Maximum Likelihood classification algorithm is an efficient method in unpredictable conditions (Jensen, 1996). The ML method works enough or well in experiments using multi-piece data (Pale et al., 2003). ML algorithms are generally preferred; unless there are specific reasons to believe that the data do not follow Gaussian distribution, or at least do not follow the infinite distribution (Pale et al., 2003). Therefore, the supervised maximum likelihood method was used to classify the satellite images. Based on field data and high-resolution images from Google Earth as reference data, six land use categories were identified, including rangeland, orchard, agriculture, bare land, outcrop, and water bodies. Reference samples were used to generate ROI (region of interest) polygons in ENVI 5.3 software to generate training areas in Landsat satellite images. After creating ROIs, the satellite images of each period were classified.

\subsection{Accuracy assessment}

Accuracy assessment is an important step in evaluating the result of the image classification; various methods may include a qualitative assessment based on expertise and a quantitative accuracy assessment based on sampling strategies (Lu and Weng, 2007). After generating an error matrix, other elements of accuracy assessment such as overall accuracy, omission error, commission error, and Kappa coefficient can be derived (Lu and Weng, 2007). Kappa coefficient is known as a useful measure for single error matrix analysis and comparing different error matrix values (Congalton 1991; Smits et al., 1999; Foody 2004). In summary, the error matrix approach is the most common method of assessing accuracy for classification ( $\mathrm{Lu}$ and Weng, 2007). Kappa coefficient is a commonly used measure of the general statistical agreement of the error matrix that considers non-diagonal elements (Lu and Weng, 2007). According to literature, an acceptable classification accuracy coefficient was considered to be at least 85\% (Foody, 2002; Thomalinson et al., 1999; Meriame Mohajane et al., 2018).

\subsection{Dynamics of single and comprehensive land-use changes}

Land-use change models can be divided into random-experimental models, dynamic models, and integrated models. Due to the simple structure and ease of operation of these models, randomexperimental models are widely used to assess the rate of land-use change (Zhang et al., 2014). The extent of land-use change over a period of time can be determined using the degree of single land-use dynamics (Wen Sun et al., 2012; Zhang et al., 2014; Schilling et al., 2010; Liu et al., 2017; Zhang et al., 2011; Yafei Li et al., 2017). The single dynamic land use index can be used quantitatively to describe the rate of land-use change at the regional scale (Redo et al., 2012). Analysis of changes in the dynamics of land use can show the intensity of land-use or land cover change through analyzing the degree of land-use dynamics (Equation 2) (Zhan Chunxiao et al., 2008).

$$
K=\frac{U b-U a}{U a} \times \frac{1}{T} \times 100 \%
$$

Where, $\mathrm{Ub}$ and $\mathrm{Ua}$ are the areas of a given user at the end and beginning of the study period, respectively. Also, $\mathrm{T}$ is the time period of the chosen time span. 
Numerous studies have used the comprehensive equation of change dynamics to determine the intensity of land-use change over a period of time (Zhang et al., 2014; Zhang et al., 2011; Li et al., 2017). Land-use change in the study area is the result of changing types of land uses. The degree of comprehensive land-use dynamics change can be used to analyze the degree of land-use change over a period of time (Equation 3) (Wen Sun et al., 2012). The degree of comprehensive dynamics of land use can be of help in the interpretation of overall change of different land use types over the given time span in a certain region.

$$
K=\left\lfloor\frac{\sum_{i=1}^{n}\left|\Delta \mathrm{LU}_{\mathrm{i}-} \mathrm{j}\right|}{2 \sum_{i=1}^{n} L U_{\mathrm{i}}}\right\rfloor \times \frac{1}{T} \times 100 \%
$$

Where, $L_{i}$ is the specific land use at the beginning of the research. $\Delta \mathrm{LU}_{\mathrm{i}-\mathrm{j}}$ Represents the area changed from a given use over a specified period of time, and $\mathrm{T}$ also represents the time to year.

\section{7. construction of change matrix}

The land use transfer matrix can display the structure of land use at one point and at a time and quantitatively describe the process of dynamics and mutual developments between land use categories at the beginning and end of the study time period. The land use transfer matrix can demonstrate the transferred rate and intensity in each land use type (Gao et al., 2016). Changes among different land-use types can be described and interpreted by a transfer matrix that shows the structural characteristics and direction of land-use change (Zhang et al., 2014).

\subsection{Economic effects of land-use change}

To investigate the effect of land-use changes from an economic point of view, the amount of costs and direct income per hectare of different land uses in the region have been estimated as present values. Then, according to the changes in land use areas, the changes in net income of different land uses in this area were calculated. Hence, the economic value of one hectare of land use is derived from the difference between average production costs and land use revenue (Equation 1) (Norman et al., 2002).

$$
\mathrm{PV}=\mathrm{TR}-\mathrm{TC}
$$

It should be noted that data related to economic indicators have been collected formally directly through referring to the Organization of Agriculture-Jahad, Ardabil Province (2019).

\section{Results and discussion}

The rate of change in each land use over the East Meshgin has been investigated, and the spatial distribution of the land use map in the given periods can be seen in Figure 2. In addition, the statistical characteristics of land use statistical tables were produced in the relevant years to analyze the quantitative characteristics of land-use changes (Table 2). 


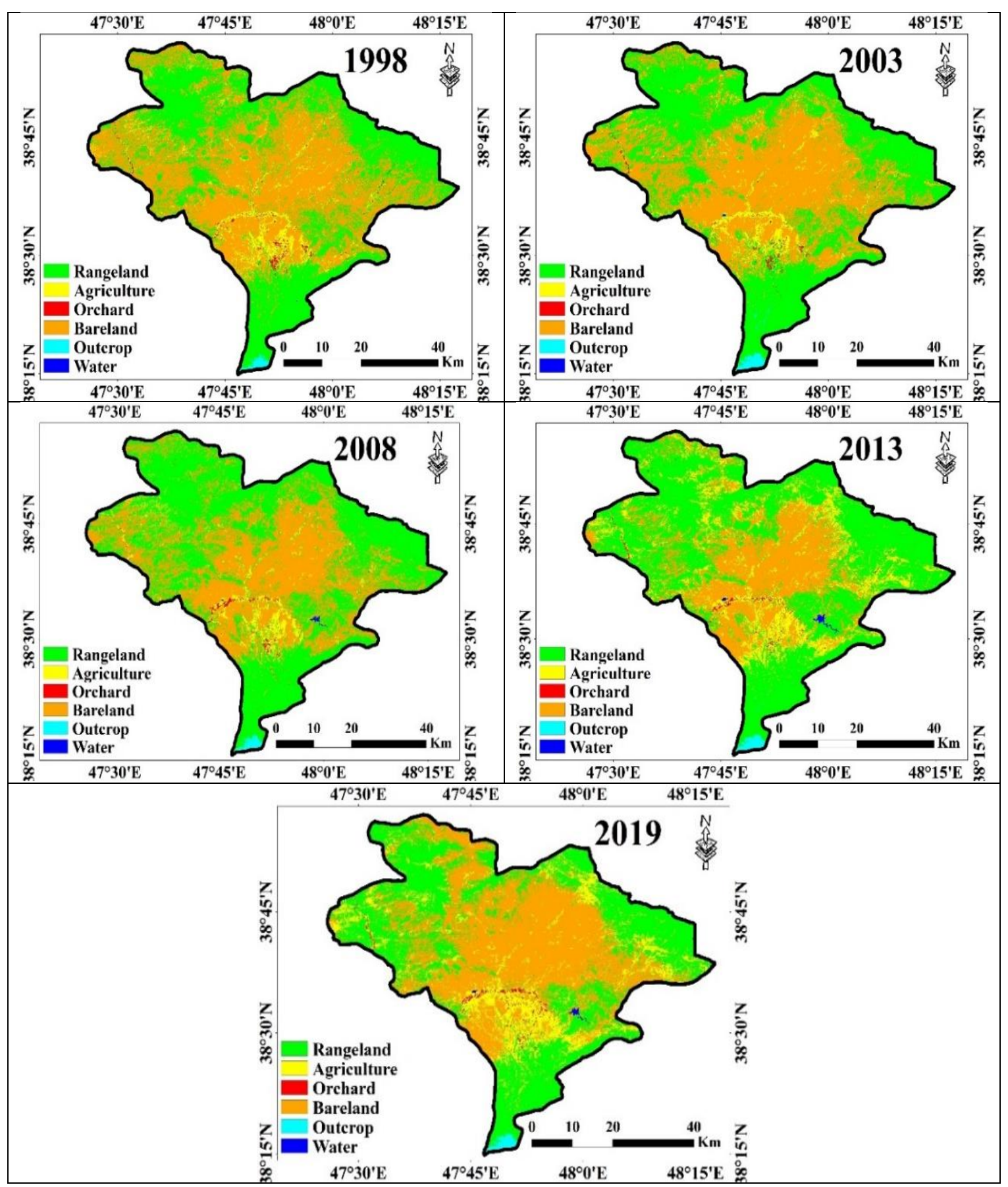

Figure 2. The land use map of East Meshgin area in different years of the given time period

As can be seen in Figure 2, the southern and northern parts of the region, which also has a high altitude, are mostly covered by rangeland, and out cropland land cover type. Additionally, the central parts of the study area are mostly covered by agricultural and bare lands. At the end of the study period, through providing the needed water from the Sabalan Dam, the land use of agriculture and orchard in the central part of the study area has increased significantly. It is clear that the predominance of rangeland and bare lands is explicit in all the studied periods. Meanwhile, the expansion and development of agricultural land is obviously had increased in 2013 and 2019. 
The area and percentage of land use in different years of the study period have been shown in Table 1. In this study, in order to investigate the economic changes caused by land-use changes in the study area, data related to income obtained for each land use per hectare, and the results presented in Table 1.

Table 1. Area and percentage of land uses in the studied periods

\begin{tabular}{|c|c|c|c|c|c|c|c|c|}
\hline \multirow{2}{*}{ Year } & \multirow{2}{*}{ Area } & \multicolumn{6}{|c|}{ Land Use Type } & \multirow[t]{2}{*}{$\begin{array}{l}\text { Total } \\
\text { Area }\end{array}$} \\
\hline & & Rangeland & Agriculture & Orchard & $\begin{array}{l}\text { Bare } \\
\text { land }\end{array}$ & Outcrop & $\begin{array}{l}\text { Water } \\
\text { body }\end{array}$ & \\
\hline \multirow{2}{*}{1998} & $\mathrm{Km}^{2}$ & 1112.88 & 163.84 & 18.73 & 1288.45 & 11.69 & 0.06 & 2595.65 \\
\hline & $\%$ & 42.7 & 6.35 & 0.76 & 49.4 & 0.47 & 0.00 & 100 \\
\hline \multirow{2}{*}{2003} & $\mathrm{Km}^{2}$ & 1212.8 & 141.25 & 13.09 & 1206.04 & 22.19 & 0.03 & 2595.4 \\
\hline & $\%$ & 46.48 & 5.7 & 0.6 & 46.21 & 0.87 & 0.01 & 100 \\
\hline \multirow{2}{*}{2008} & $\mathrm{Km}^{2}$ & 1368.35 & 127.39 & 13.71 & 1067.01 & 17.26 & 1.92 & 2595.64 \\
\hline & $\%$ & 52.6 & 4.9 & 0.55 & 40.9 & 0.68 & 0.07 & 100 \\
\hline \multirow{2}{*}{2013} & $\mathrm{Km}^{2}$ & 1445.75 & 386.19 & 14 & 724.8 & 20.72 & 4.21 & 2595.67 \\
\hline & $\%$ & 55.4 & 14.81 & 0.55 & 27.77 & 0.71 & 0.17 & 100 \\
\hline \multirow{2}{*}{2019} & $\mathrm{Km}^{2}$ & 1127.06 & 427.01 & 17.65 & 1005.9 & 15.17 & 2.88 & 2595.67 \\
\hline & $\%$ & 43.2 & 16.37 & 0.7 & 38.56 & 0.6 & 0.14 & 100 \\
\hline \multicolumn{2}{|c|}{$\begin{array}{l}\text { Value per hectare } \\
\text { of land use (USD)* }\end{array}$} & 115.87 & 370.8 & 1861.73 & 54.07 & - & - & - \\
\hline
\end{tabular}

According to the results of Table 1, the highest land-use area in 1998 is related to bare land with $49 \%$ of the total land area, and the lowest amount is related to water land use and outcrop, having zero and $0.44 \%$ respectively. In contrast, the statistics of the year 2019 show that rangeland land use $(43.16 \%)$ has the highest area, and water body has the lowest extent with $0.11 \%$ contribution. Due to the operation of Sabalan Dam and since the year 2008, the area of agricultural use increased in the study area. Given that there have been many changes in the agricultural sector, especially the development of modern mechanization methods, it can be said that these changes are expected. Furthermore, the water body land use in the study area has been increasing during these years, mainly because of the Sabalan dam construction. According to the assessments made in the area, there is no limitation in terms of water availability. According to field surveys and interview with local farmers, the constraints on access to water in some cases has been resolved by considering the distribution of water supply sources, including dams, springs, and rivers.

Figure 3 shows the net income trend in agricultural land use, orchards, rangeland, and bare lands in different years of the study period. 


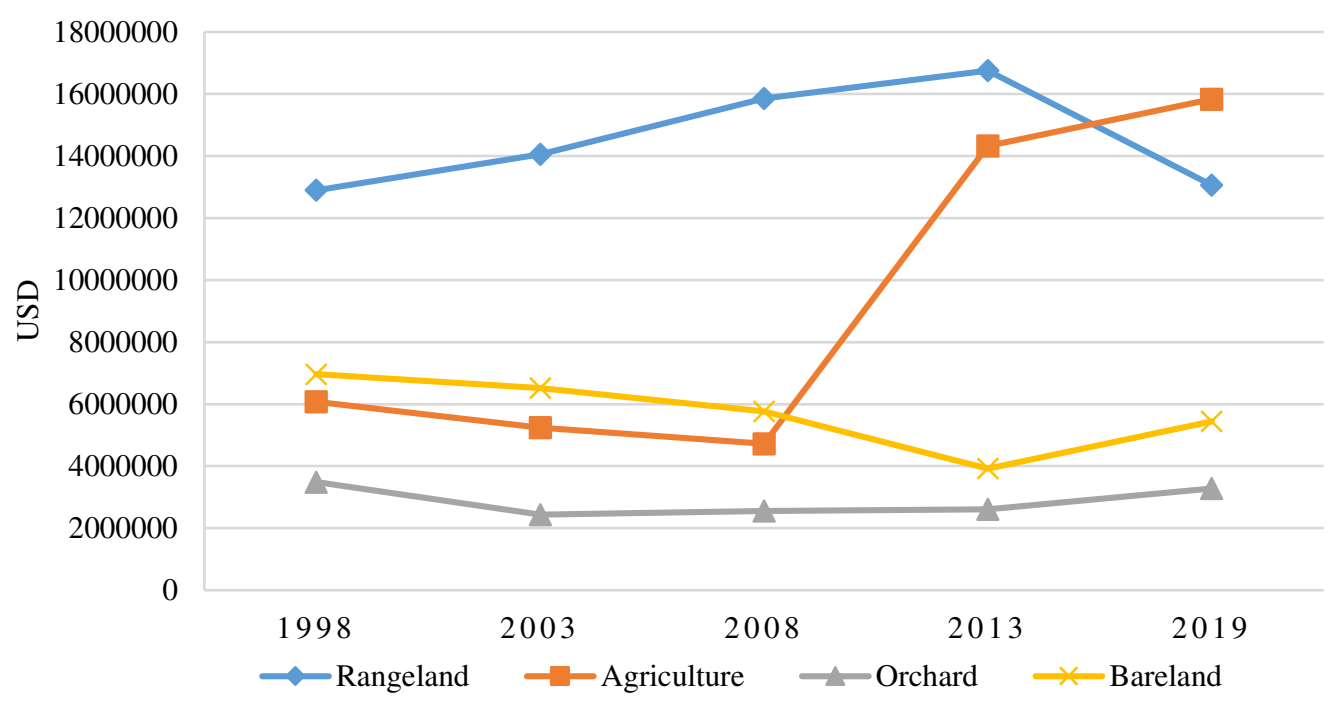

Figure 3: Changes in net income of the main land uses in the studied years of the period under study

It can be seen that the net income of agricultural land use had an increasing trend since 2008. It can be attributed to the interest of landowners and the special attention of those involved in agriculture and water resources through a pressurized irrigation system in downstream lands of the dam based on the storage capacity of Sabalan Dam. As well as incentives and monetary support policies from governmental agencies have intensified the expansion of agricultural land use over the study area. Therefore, this trend has led to the conversion of other land uses to agricultural lands due to its cost-effectiveness and acceptable productivity. An increase of about 200 percent in agricultural land use in 2013 compared to 2008 led to an increase of about $9596.3 \$$ and a 47 percent decrease in abounded lands in these years also reduced 1850.3 \$. Also, the decrease in rangeland use in 2019 compared to 2013 has reduced revenue by $3636.6 \$$. It should be noted that the growth rate of revenue in all land uses in 2019 compared to 1998 has grown by 278 percent (equivalent to 8193833 \$).

\subsection{Classification accuracy assessment}

The accuracy of the classification was assessed using confusion matrix information, which the overall accuracy for classifying the years studied is reported in Table 2. According to Table 2, the extracted Kappa coefficient for the years 1998, 2003, 2008, 2013 and 2019 are equal to 0.85, 0.77, $0.96,0.98,0.97 \%$, respectively. The value of Kappa coefficient proved the acceptable accuracy of classification results.

Table 2: User and producer accuracy values for different land-use classes

\begin{tabular}{|c|c|c|c|c|c|c|c|c|c|c|}
\hline Land use & \multicolumn{2}{|c|}{1998} & \multicolumn{2}{c|}{2003} & \multicolumn{2}{c|}{2008} & \multicolumn{2}{c|}{2013} & \multicolumn{2}{c|}{2019} \\
\hline & User & Prod & User & Prod & User & Prod & User & Prod & User & Prod \\
\hline Rangeland & 91.54 & 96.93 & 79.85 & 96.67 & 99.5 & 98 & 99.22 & 99.22 & 99.17 & 99.18 \\
\hline Agriculture & 76.48 & 91.04 & 75.2 & 96.44 & 81.85 & 91.69 & 95.89 & 95.89 & 89.82 & 97.43 \\
\hline
\end{tabular}




\begin{tabular}{|c|c|c|c|c|c|c|c|c|c|c|}
\hline Orchard & 88.80 & 85.98 & 94.76 & 79.6 & 89.62 & 93.76 & 86.74 & 86.74 & 96.8 & 83.59 \\
\hline Bare land & 94.09 & 83.75 & 99.91 & 94.74 & 97.49 & 99.52 & 99.49 & 99.49 & 99.34 & 98.7 \\
\hline Outcrop & 99.89 & 99.03 & 93.93 & 98.3 & 99.41 & 98.48 & 99.5 & 99.5 & 99.82 & 98.22 \\
\hline Water & 100.00 & 92.86 & 100 & 100 & 100 & 99.47 & 100 & 100 & 100 & 99.34 \\
\hline $\begin{array}{c}\text { Overall } \\
\text { Accuracy }\end{array}$ & 92.15 & \multicolumn{2}{|c|}{94.9} & \multicolumn{2}{|c|}{98.22} & 98.92 & 98.43 \\
\hline $\begin{array}{c}\text { Kappa } \\
\text { Coefficient }\end{array}$ & 0.85 & \multicolumn{2}{|c|}{0.77} & \multicolumn{2}{c|}{0.96} & \multicolumn{2}{|c|}{0.98} & \multicolumn{2}{c|}{0.97} \\
\hline
\end{tabular}

\subsection{Analysis of land uses transfer using transfer matrix}

The land use transfer matrix in the studied periods is reported in Table 3 . This matrix indicates the possibility of changing and transferring the land uses to each other.

Table 3. Land-use transfer matrix between the studied periods $\left(\mathrm{Km}^{2}\right)$

\begin{tabular}{|c|c|c|c|c|c|c|c|c|c|}
\hline \multirow[t]{2}{*}{ From } & \multirow[t]{2}{*}{ To } & \multicolumn{2}{|c|}{ 1998-2003 } & \multicolumn{2}{|c|}{ 2003-2008 } & \multicolumn{2}{|c|}{$2008-2013$} & \multicolumn{2}{|c|}{ 2013-2019 } \\
\hline & & $\%$ & Area $\left(\mathrm{km}^{2}\right)$ & $\%$ & Area $\left(\mathrm{km}^{2}\right)$ & $\%$ & Area $\left(\mathrm{km}^{2}\right)$ & $\%$ & Area $\left(\mathrm{km}^{2}\right)$ \\
\hline \multirow{5}{*}{ Rangeland } & Agriculture & 2.73 & 30.42 & 2.52 & 30.61 & 7.93 & 108.61 & 8.88 & 127.66 \\
\hline & Orchard & 0.31 & 3.55 & 0.15 & 1.98 & 0.03 & 0.52 & 0.06 & 0.96 \\
\hline & Bare land & 23.72 & 264.02 & 9.70 & 117.99 & 4.09 & 67.13 & 18.65 & 269.74 \\
\hline & Outcrop & 0.02 & 0.23 & 0.15 & 1.83 & 0.31 & 4.25 & 0.01 & 0.28 \\
\hline & Water & 0.003 & 0.04 & 0.06 & 0.73 & 0.07 & 0.96 & 0.00 & 0.00 \\
\hline \multirow{5}{*}{ Agriculture } & Rangeland & 12.72 & 20.85 & 25.85 & 36.52 & 18.74 & 23.88 & 11.17 & 43.14 \\
\hline & Orchard & 4.17 & 6.84 & 4.5 & 6.4 & 5.22 & 6.66 & 2.26 & 8.74 \\
\hline & Bare land & 28.75 & 47.11 & 30.51 & 43.1 & 12.00 & 15.29 & 35.47 & 136.99 \\
\hline & Outcrop & 0.01 & 0.02 & 0.05 & 0.08 & 0.19 & 0.25 & 0.002 & 0.01 \\
\hline & Water & 0.00 & 0.00 & 0.007 & 0.1 & 0.36 & 0.46 & 0.00 & 0.00 \\
\hline \multirow{5}{*}{ Orchard } & Rangeland & 6.19 & 1.16 & 10.54 & 1.38 & 13.12 & 1.8 & 5.5 & 0.77 \\
\hline & Agriculture & 21.40 & 4.01 & 53.62 & 7.02 & 38.00 & 5.21 & 46.00 & 6.44 \\
\hline & Bare land & 1.60 & 0.3 & 0.68 & 0.09 & 0.36 & 0.05 & 0.35 & 0.05 \\
\hline & Outcrop & 0.00 & 0 & 0.07 & 0.01 & 0.00 & 0 & 0.00 & 0 \\
\hline & Water & 0.00 & 0 & 0.00 & 0 & 0.00 & 0 & 0.00 & 0 \\
\hline \multirow{5}{*}{ Bare land } & Rangeland & 13.01 & 167.75 & 21.90 & 264.15 & 21.73 & 231.94 & 4.33 & 31.45 \\
\hline & Agriculture & 4.87 & 62.83 & 2.83 & 34.23 & 17.93 & 191.39 & 12.93 & 93.78 \\
\hline & Orchard & 0.05 & 0.73 & 0.06 & 0.74 & 0.01 & 0.17 & 0.16 & 1.2 \\
\hline & Outcrop & 0.006 & 0.08 & 0.05 & 0.66 & 0.03 & 0.39 & 0.005 & 0.04 \\
\hline & Water & 0.00 & 0 & 0.07 & 0.95 & 0.08 & 0.96 & 0.001 & 0.01 \\
\hline \multirow{5}{*}{ Outcrop } & Rangeland & 73.13 & 8.55 & 29.83 & 6.62 & 6.66 & 1.15 & 20.70 & 4.29 \\
\hline & Agriculture & 1.11 & 0.13 & 1.80 & 0.4 & 0.75 & 0.13 & 5.45 & 1.13 \\
\hline & Orchard & 0.00 & 0 & 0.04 & 0.01 & 0.00 & 0 & 0.04 & 0.01 \\
\hline & Bare land & 18.22 & 2.13 & 42.54 & 9.44 & 0.92 & 0.16 & 2.99 & 0.62 \\
\hline & Water & 0.17 & 0.02 & 0.18 & 0.04 & 0.05 & 0.01 & 0.09 & 0.02 \\
\hline \multirow{5}{*}{ Water } & Rangeland & 0.00 & 0.00 & 0.00 & 0.00 & 4.16 & 0.08 & 7.36 & 0.31 \\
\hline & Agriculture & 0.00 & 0.00 & 0.00 & 0.00 & 0.00 & 0 & 16.62 & 0.7 \\
\hline & Orchard & 0.00 & 0.00 & 0.00 & 0.00 & 0.00 & 0 & 0.00 & 0 \\
\hline & Bare land & 0.00 & 0.00 & 0.00 & 0.00 & 0.52 & 0.01 & 4.27 & 0.18 \\
\hline & Outcrop & 0.00 & 0.00 & 0.00 & 0.00 & 0.52 & 0.01 & 4.27 & 0.18 \\
\hline
\end{tabular}

According to the results of Table 3, in the period 1998-2003, the most changes were attributed to rangeland conversion to bare lands with 264.02 square kilometers. In other words, in this period, $23.72 \%$ of the rangeland has become bare lands. Also, $21.9 \%$ of bare lands were transferred to rangelands in 2003 at the end of the period. Additionally, in the period of 2008-2013, the highest transfer was related to the bare lands, of which 231.94 square kilometers from this land use were transferred to the rangeland. In the same period, the transition from rangeland use to agricultural use was significant compared to previous periods, so that 101.61 square kilometers $(7.93 \%$ of rangelands) has become converted to agriculture use. It can be said that following the changes in the use of rangeland for agriculture, it has increased the economic income by $37676 \$$ in the region. 
In the final period, 2013-2019, the most transfer has been related to rangeland use, so that 269.74 square kilometers have been transferred from rangeland use to bare land use. In the same period, 127.66 square kilometers, i.e., $8.88 \%$ of the rangeland, have been converted to agricultural land use.

\subsection{Analysis of land-use change dynamics in the study area}

The degree of single dynamics was calculated according to Equation 2, the results of which are reported in Table 4.

Table 4. Single land-use variation dynamic degree from 1998 to 2019.

\begin{tabular}{|l|l|l|l|l|l|}
\hline Land Use Type & $1998-2003$ & $2003-2008$ & $2008-2013$ & $2013-2019$ & $1998-2019$ \\
\hline Rangeland & 1.79 & 2.05 & 1.41 & -3.522 & 0.05 \\
\hline Agriculture & -2.75 & -1.56 & 50.78 & 1.69 & 6.42 \\
\hline Orchard & -6.02 & 0.76 & 0.51 & 4.17 & -0.23 \\
\hline Bare land & -1.27 & -1.84 & -8.01 & 6.2 & -0.87 \\
\hline Outcrop & 17.95 & -3.55 & 5 & -4.2 & 1.19 \\
\hline Water & 82.68 & 83.67 & 29.64 & -5.06 & 187.04 \\
\hline
\end{tabular}

As can be seen, in each period, the most relevant change is related to water use, which has been positive in all periods except the period of 2013-2019. Among other land uses, the highest rate of change related to agricultural use with a value of +50.78 occurred during 2013-2019. It is worth mentioning that during this period, the Sabalan Dam had been started to operation in the region. Based on the results related to the total period, i.e., 1998-2019, apart from water land use, which had a positive growth rate of $187 \%$, the biggest change was related to agricultural land use with a growth rate of +6.42 and the lowest change rate was related to rangelands with a change rate of 0.05 . And orchard land use with a change rate of -0.23 and bare lands with a change rate of -0.87 have had negative growth. Figure 4 shows the graphs related to the results of the equation of the degree of single dynamics land-use change in different periods.

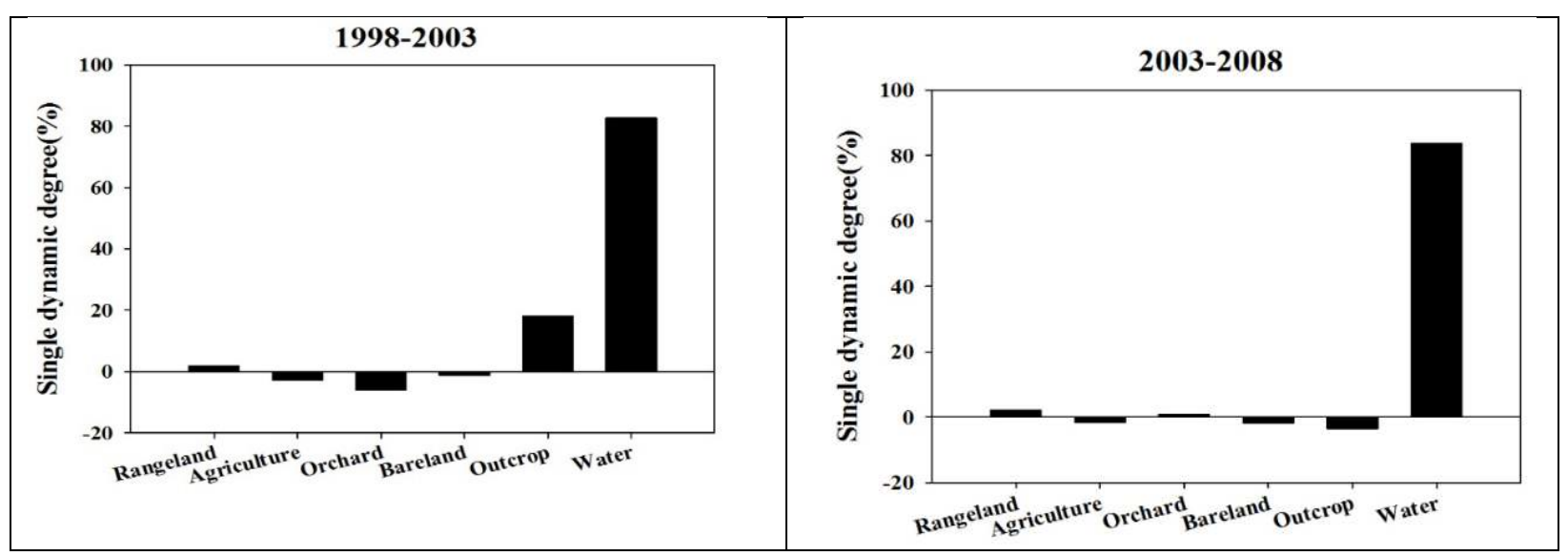




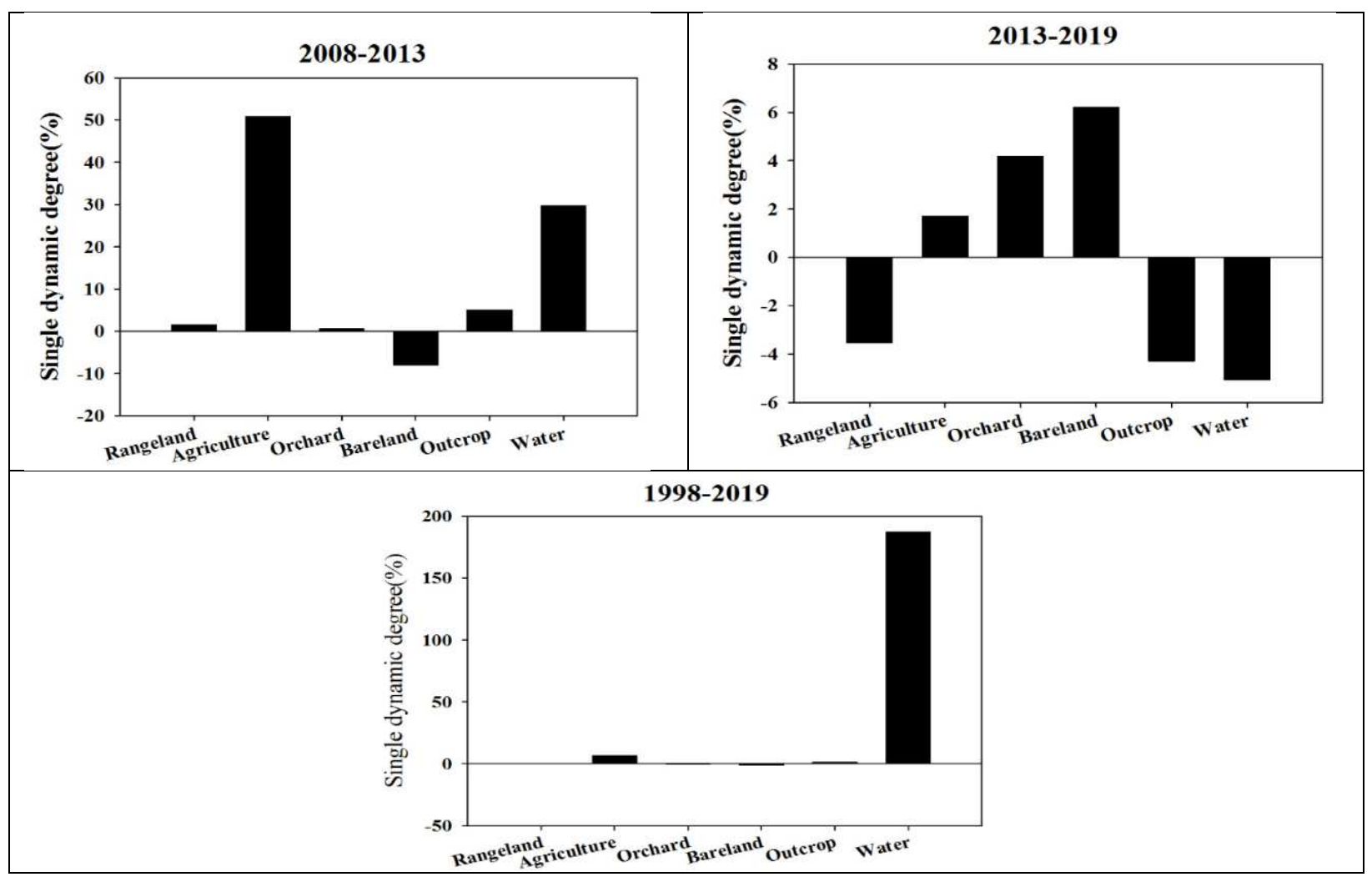

Figure 4. Degree of dynamics of individual land-use change in the East Meshgin area

The degree of comprehensive dynamics of land-use change according to Equation 2 is shown in Figure 5. 


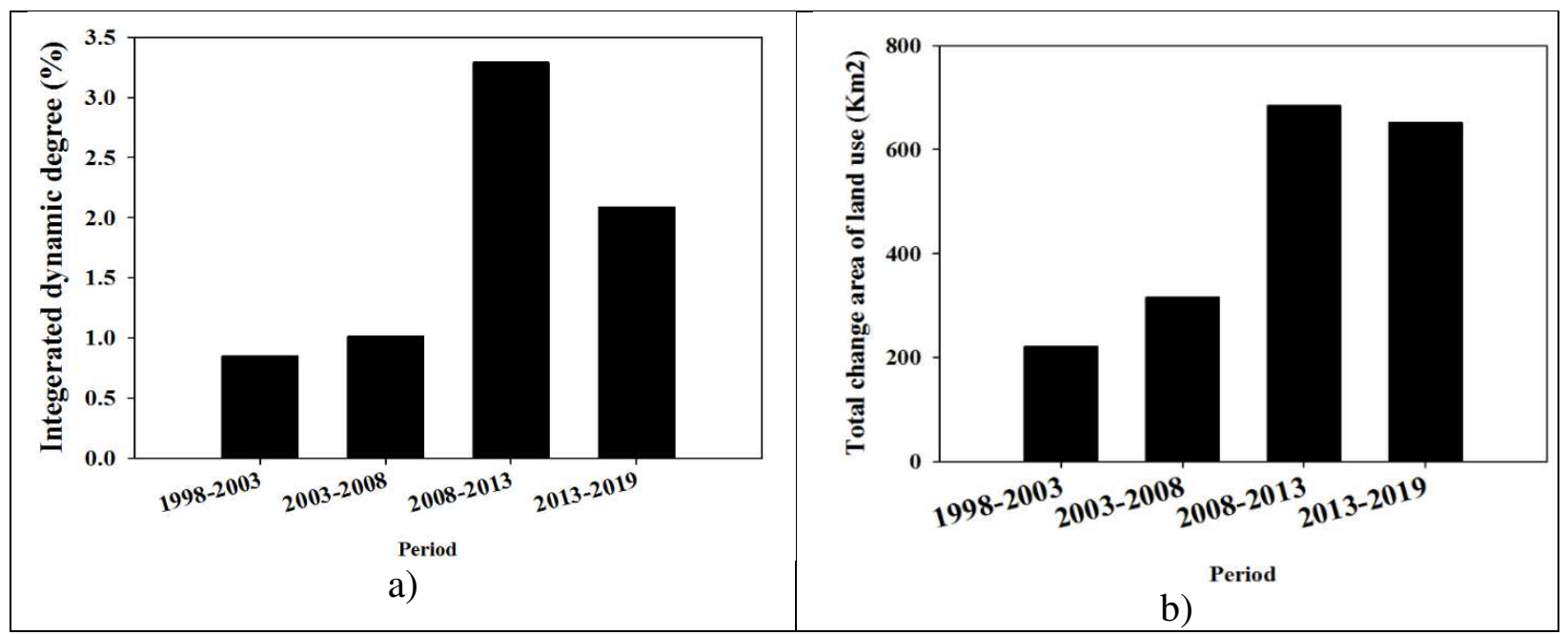

Figure 5. Degree of comprehensive land-use change (A) and total land-use change (B) in each period

According to the results of Figure 5, the highest degree of dynamics of comprehensive land-use change is related to the period 2008-2013, i.e., in the years of operation and water exploitation of Sabalan dam, and the lowest degree of dynamics is related to the period 2003-2009 with +3.29 and $+0.85 \%$, respectively. Additionally, the highest total land use change occurred in the period 20082013 with 684.41 square kilometers, and the lowest total land use change occurred in the period 1998-2003 with 212.231 square kilometers.

\section{Conclusion}

The analysis of land-use change over a period of time and consequent years is necessary to sound planning and sustainable management and natural resources conservation. Assessing the economic impacts of land use change lead to more comprehensive results and livelihood improvement of farmers and watershed communities. East Meshgin region in Ardabil province, which is one of the important agricultural areas in the province and even in Iran, has been affected by significant divers of land use change in recent years. According to the results, the overall pattern of land use conversions has intensified through the operation of the constructed Sabalan reservoir dam. The results of this study, which was examined from 1998 to 2019, show that the most change is related to water body extent, which is attributed to the construction and operation of Sabalan dam. Apart from water body extent, agricultural land use has had the most change in the overall period in an incremental manner by an increase of $6.42 \%$. Among the intermediate periods, the highest increase in agricultural land use is related to the period of 2008-2013, which is due to expansion of irrigated agriculture and allocated water released from constructed reservoir. The cost-effectiveness and high productivity of irrigated lands is another main driver of transferring rangelands to cultivated areas. The amount of this increase is about 200 percent in agricultural lands in 2013 compared to 2008 , taht has led to an increase in revenue of 95,969,304 \$. According to the results, the most land conversions to agricultural land occurred from bare lands with 191.39 square kilometers, followed by rangeland with 108.61 square kilometers. Another result of the research in the whole period of the study is the significant growth of agricultural lands, which means $160 \%$ rate. Taking into account the exchange rate and per hectare economic revenue of agricultural land in 2019 , which is about 370.8 , this increase in agricultural lands is estimated to be around 97.6 million $\$$. 
In general, the growth rate of revenue in all land uses in 2019 compared to 1998, has grown by 278 percent. Highest GDP value of agricultural products are related to potatoes (37.2\%), and wheat (23\%) in the Ardabil province. East Meshgin is one of the main centers of agricultural production in Ardabil province, with the benefit of potentials, climatic conditions and extensive production resources. The rural community makes up $56.8 \%$ of the population of the study area, and the agricultural sector is the dominant sector in the rural economic system of the study area. Tomatoes, mung beans, cucumbers and squash can be mentioned among the marketable products of this region, and the main garden products of this region include apricots, apples, pears and grapes. The main source of income for the people of the region is agricultural and horticultural products. In addition to agriculture, animal husbandry has flourished in the region in the past. High dependence on agriculture is an important factor in increasing the agricultural land extent. Insufficient use of modern machinery and equipment and lack of modern methods of agricultural exploitation and non-use of high-yield cultivars are some of the things that can be useful in increasing the productivity of agricultural lands. Low efficiency of using resources, inputs of production, and labor is one of the important features of agricultural lands in the region. Therefore, instead of improving productivity, increasing the area under cultivation in the region has caused a widespread change in land use in the region. This study is designed to facilitate policymakers, planners, and other stakeholders in this sector to adopt the best land management strategies. The following recommendations are provided to proper land management in the study area. Predicting population and development needs in this area to ensure the wise use and allocation of limited land resources among competitive land uses. In addition, to ensure better use of resources, the Ministry of Jihad for Agriculture must take steps to identify fertile and non-productive agricultural land and limit the conversion of good agricultural land to non-agricultural use within the legal frameworks. There is a need for further studies to investigate changes in water quality due to the land-use change.

\section{References:}

Al-Razzaq Abd, H.A. \& Alnajjar., H.A. 2013 Maximum Likelihood for Land-Use/Land-Cover Mapping and Change Detection Using Landsat Satellite Images: A Case Study "South Of Johor". International Journal of Computational Engineering Research, 6(3), 26-33.

Amini parsa, V. \& Salehi, E. 2016 Spatio-temporal analysis and simulation pattern of land use/cover changes, case study: Naghadeh, Iran. Journal of urban management. 5(2016), 43-51.

Anvari, A. \& Valaie, M. 2015 Evaluation of the Effects of water level decline of Urmia Lake in sustainable rural Development: Case study: Central Marhamat Abad rural district, Miandoab County. Bulletin of Environment, Pharmacology and Life Sciences. 4(7), 65-71.

Aspinall, R. 2004 Modelling land use change with generalized linear models - a multi-model analysis of change between 1860 and 2000 in Gallatin Valley, Montana. Journal of Environmental Management. 72, 91-103.

Butt, A., Shabbir, R., Ahmad, S.S. \& Aziz, N. 2015 Land use change mapping and analysis using remote sensing and GIS: a case study of Simly watershed, Islamabad, Pakistan. Egypt. J. Rem. Sens. Space Sci. 18, 251-259.

Congalton, R. G. 1991 A review of assessing the accuracy of classifications of remotely sensed data. Remote Sensing of Environment. 37(1), 35-46.doi:10.1016/0034-4257(91)90048-b.

Chunxiao, Z., Liu, Z. \& Nan, Z. 2008 Using remote sensing and GIS to investigate land use dynamic change in western plain of jilin province. The International Archives of the Photogrammetry, Remote Sensing and Spatial Information Sciences. Vol. XXXVII. Part B7. Beijing 2008.

Cihlar, J., Xiao, Q. \& Chen, J. 1998 Classification by progressive generalization: a new automated methodology for remote sensing multichannel data. International Journal of remote sensing. 14(19), 2685-2704. 
Civco, D.L. 1989 Topographic normalization of Landsat Thematic Mapper digital imagery. Photogram. Eng. Remote Sens. 55(9), 1303-1309.

DeFries, R.S., Rudel, T., Uriarte, M. \& Hansen, M. 2010 Deforestation driven by urban population growth and agricultural trade in the twenty-first century. Nat. Geosci. 3, 178-181.

Fahsi, A. 1993 Modeling topographic effects on digital remotely sensed data. Ph.D. dissertation, Department of Forest Resources, University of Idaho, Moscow, Idaho, p. 122

Fahsi, A., Tsegaye, T., Tadesse, W. \& Coleman, T. 2000 Incorporation of digital elevation models with Landsat-TM data to improve land cover classification accuracy. Forest Ecology and Management. 128(2000), 57-64.

Foody, GM. 2002 Status of land cover classification accuracy assessment. Remote Sensing of Environment. 80(2002), 185-201.

Foody, GM. 2004 Thematic Map Comparison: Evaluating the Statistical Significance of Differences in Classification Accuracy. Photogrammetric Engineering \& Remote Sensing. 5(70), 627-633.

F. J, Gao., L. Q, Ma., Shan, M. p., et al. 2016 Land use/cover change and hot spots analysis in muling city of Helonjing province. Areal Research Development. 35, 126-130.

Gautam, N.C. \& Chennalah, G.CH. 1985 Land-use and land-cover mapping and change detection in Tripura using satellite LANDSAT data. International Journal of Remote Sensing. 6(3-4), 517-528.

Gilabert, M.A., Conse, C., Maselli, F. \& Bottai, L. 1993 Topographic normalization of TM scenes through the use of atmospheric correction method and digital terrain models. Photogrammetric Engineering \& Remote Sensing. 59(12), 1745-1753.

Hamad, R., Balzter, H. \& Kolo, K. 2018 Simulation of land use/cover change dynamics in future based on Markov-CA model. Sustainability. 10, 3421. doi:10.3390/su10103421

He, Ch., Okada, N., Zhang, Q., Shi, P. \& Li, J. 2008 Modeling dynamic urban expansion processes incorporating a potential model with cellular automata. Landscape Urban Plan. 86 (1), 79-91.

Jensen, J.R. 1996 Introductory Digital Image Processing: A Remote Sensing Perspective. Englewood Cliffs, Prentice-Hall, New Jersey.

Kamrul, I., Jashimuddin, M. \& Nath, B. 2018 Land use classification and change detection by using multitemporal remotely sensed imagery: The case of Chunati wildlife sanctuary, Bangladesh. The Egyption Journal of remote sensing and Space sciences. 21 (2018), 37-47.

Khawaldah, H.A., Farhan, 1. \& Alboun, N.M. 2020 Simulation and prediction of land use and land cover change using GIS, remote sensing and CA-Markov model. Global Journal of Environmental Science and Management. 6(2), 215-232.

Lambin, E.F. 1997 Modelling and monitoring land-cover change processes in tropical regions. Progress in Physical Geography. 21, 375-393.

Lambin, E.F., Geist, H.J. \& Lepers, E. 2003 Dynamics of land-use and land-cover change in tropical regions. Annual review of Environment and resources. 28, 205-241.

Li, M., Wu, J. \& Deng, X. 2016 Land use change and soil carbon sequestration in China: Where does it pay to conserve? Regional Environmental change. 16, 2429-2441.

Li, Yafei., Liu, Gaohuan. \& Huang, Chong. 2017 Dynamic Changes Analysis and Hotspots Detection of Land Use in the Central Core Functional Area of Jing-Jin-Ji from 2000 to 2015 Based on Remote Sensing Data. Mathematical Problems in Engineering. 16 pages.

Liang, D., Zuo, Y. \& Huang, L. 2015 Evaluation of the Consistency of MODIS Land Cover Product (MCD12Q1) Based on Chinese $30 \mathrm{~m}$ GlobeLand30 Datasets: A Case Study in Anhui Province, China. International Journal of Geo-information. 2015(4), 2519-2541.

Lin, C., Wu, C.C. \& Tsogt, K. 2015 Effects of Atmospheric Correction and Pansharpening on LULC Classification Accuracy using WorldView-2 Imagery. Information progressing in Agriculture. 1(2), 25-36.

Liu, S., Wang, D. \& Hong, L. 2017 Ecological Land Fragmentation Evaluation and Dynamic Change of a Typical Black Soil Farming Area in Northeast China. Sustainability. 9(2), 300.

Lu, D., Weng, Q. (2007). A survey of image classification methods and techniques for improving classification performance, International Journal of Remote Sensing, 5(28):823-870. 
Md Abdullah, A.Y., Masrus, A. \& Adnan, M.S.G. 2019 Spatio-temporal Patterns of Land Use/Land Cover Change in the Heterogeneous Coastal Region of Bangladesh between 1990 and 2017. Remote sensing. 11(2019), 790.

-Meshesha, T.W., Tripathi, S.K. \& Khare, D. 2016 Analyses of land use and land cover change dynamics using GIS and remote sensing during 1984 and 2015 in the Beressa Watershed Northern Central Highland of Ethiopia. Modeling earth systems and environment. 2(4), 1-12.

Mohajane, M., Essahlaoui, A. \& Oudija, F. 2018 Land Use/Land Cover (LULC) Using Landsat Data Series (MSS, TM, ETM+ and OLI) in Azrou Forest, in the Central Middle Atlas of Morocco. Environments. 2018(5), 131.

Mondal, M.S., Sharma, N., Garg, P.K. \& Kappas, M. 2016 Statistical independence test and validation of CA Markov land use land cover (LULC) prediction results. The Egyptian Journal of Remote Sensing and Space Science. 19(2), 259-272.

Norman, D.W., Burton, R.O., Freyenberger, S.G., Jones, R.D. \& Jost, J. 2002 Financial Analysis for Sustainable Agriculture, Part I: Gross Margin Analysis, Paper 1A: Definitions and Enterprise Analysis' Kansas Sustainable Agricultural Series Paper Number 8, Kansas Center for Sustainable Agriculture and Alternative Crops.

Othow, O.O., Gebre, S.L. \& Gemeda, D.O. 2017 Analyzing the Rate of Land Use and Land Cover Change and Determining the Causes of Forest Cover Change in Gog District, Gambella Regional State, Ethiopia. Journal of remote sensing and GIS. 4(6), 219.

Pal, M. \& Mather, P.M. 2003 An assessment of the effectiveness of decision tree methods for land cover classification. Remote Sensing of Environment. 86(2003), 554-565.

Redo, D.J., Aide, T.M. \& Clark, M.L. 2012 Impacts of internal and external policies on land change in Uruguay, 2001-2009. Environmental conservation. 39(2), 122-131.

Satyanarayana, B., Thierry, B., Loseen, D. \& Raman, A.V. 2001 Remote sensing in mangrove ResearchRelationship between vegetation indices and dendrometric parameters: a case for Coringa, east coast of India. Presented at the $22^{\text {nd }}$ Asian conference on remote sensing. 5-9 Nov 2001, Singapore.

Schilling, K.E., Chan, K-S. \& Zhang, Y-K. 2010 Quantifying the effect of land use land cover change on increasing discharge in the Upper Mississippi River. Journal of Hydrology. 387(2010), 343-345.

Sen, G., Bayramoglu, M.M. \& Toskoy, D. 2015 Spatiotemporal changes of land use patterns in high mountain areas of Northeast Turkey: a case study in Maçka. Environmental Monitoring and assessment. 187(8).doi:10.1007/s10661-015-4727-8

Smits, P.C., Dellepiane, S.G. \& Schowengerdt, R.A. 1999 Quality assessment of image classification algorithms for land-cover mapping: A review and a proposal for a costbased approach. International Journal of Remote Sensing. 8(20), 1461-1486.

Sujatha, P., Baskaran, R. \& Hajeeranbeevi, N. 2014 Land use and land cover change detection in Tiruchirappalli District uising Remote Sensing and GIS. Journal of Engineering Research and Applications. 11(4), 34-41.

Thomlinson, J.R., Bolstad, P.V. \& Cohen, W.B. 1999 Coordinating Methodologies for Scaling Land cover Classifications from Site-Specific to Global: Steps toward Validating Global Map Products. Remote sensing of environment. 1(70), 16-28.

Tsai, Y., Zia, A. \& Koliba, C. 2015 An interactive land use transition agent-based model (ILUTABM): Endogenizing human-environment interactions in the western Missisquoi watershed. Land use policy. 49(2015). 161-176.

Wen Sun, J., Qi Wang, H. \& Fu Zhang, Y. 2012 Analysis of Land Use Dynamic in Genhe City Based on GIS and RS. Applied Mechanics an,d Materials. 256(259), 2298-2302.

Xiangmei, L., Ying, W., Jiangfeng, L. \& Bin, L. 2016 Physical and socioeconomic driving forces of landuse and land-cover changes: A case study of Wuhan City, China. Discrete dynamics in nature and society. 2016, 11 pages.

Zeng, Y.N., Wu, G.P., Zhan, F.B. \& Zhang, H.H. 2008 Modeling spatial land use pattern using autologistic regression. The International Archives of the Photogrammetry, Remote Sensing and Spatial Information Sciences. Vol. XXXVII. Part B2. Beijing 2008. 
Zhang, H., Zhou, L., Chen, M. \& Ma, W. 2011 Land Use Dynamics of the Fast-Growing Shanghai Metropolis, China (1979-2008) and its Implications for Land Use and Urban Planning Policy. Sensors. 11, 1794-1809.

Zhang, T., Zhang, X., Xia, D. \& Liu, Y. 2014 An Analysis of Land Use Change Dynamics and Its Impacts on Hydrological Processes in the Jialing River Basin. Water. 6, 3758-3782.

Zhang, L.T., Ding, W.R., Zhou, Y. \& Zhang, L. 2007 Study on land use and land cover change. Environ. Sci. 26, 7-10. 


\section{Figures}
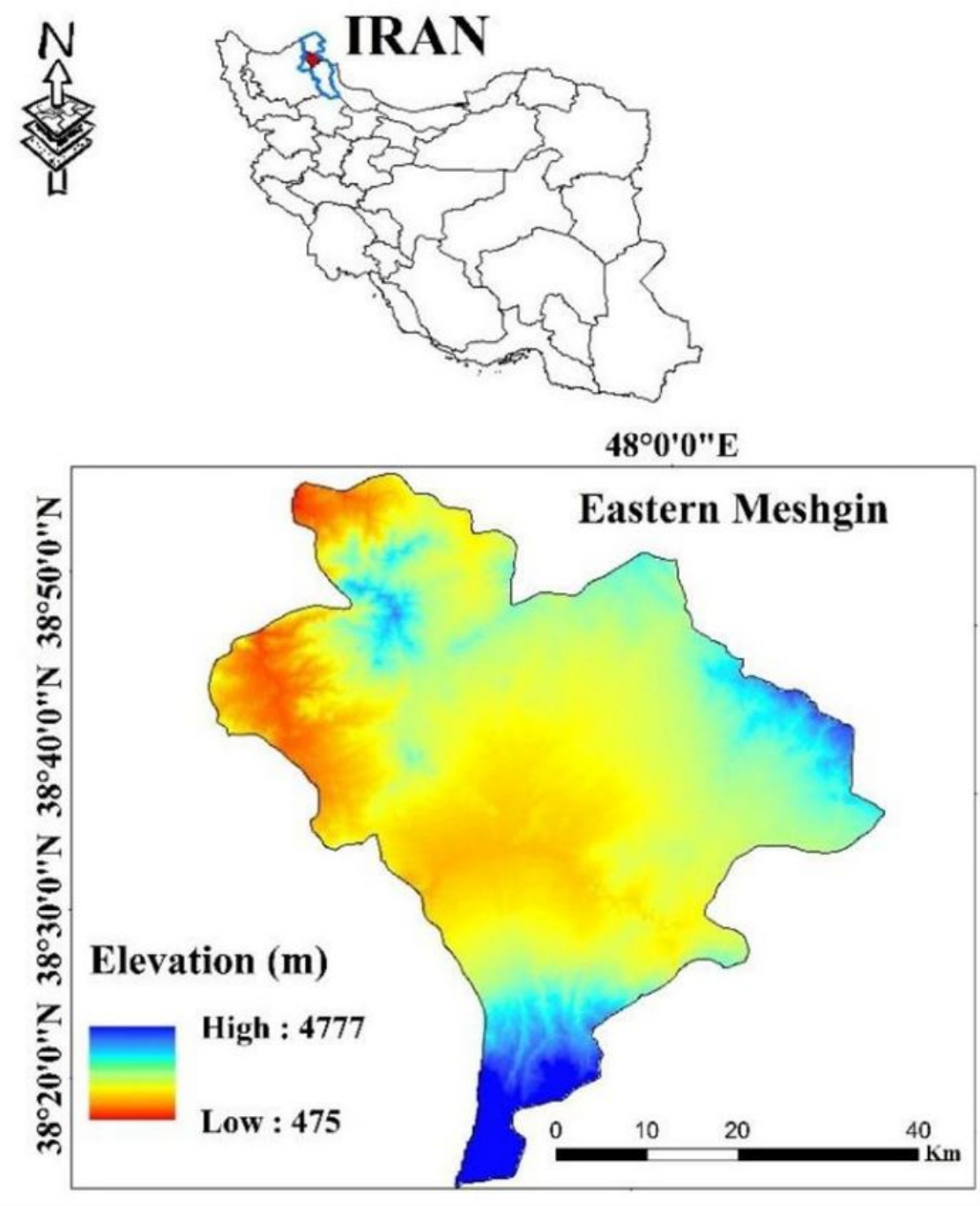

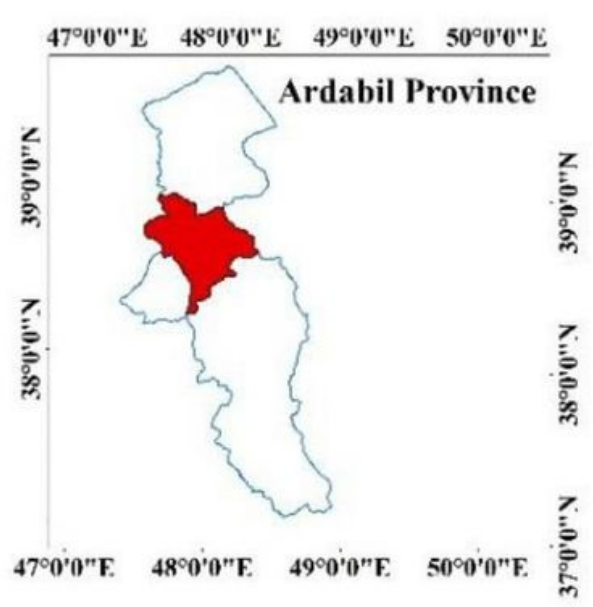

\section{Figure 1}

The location of the study area in Ardabil province Note: The designations employed and the presentation of the material on this map do not imply the expression of any opinion whatsoever on the part of Research Square concerning the legal status of any country, territory, city or area or of its authorities, or concerning the delimitation of its frontiers or boundaries. This map has been provided by the authors. 


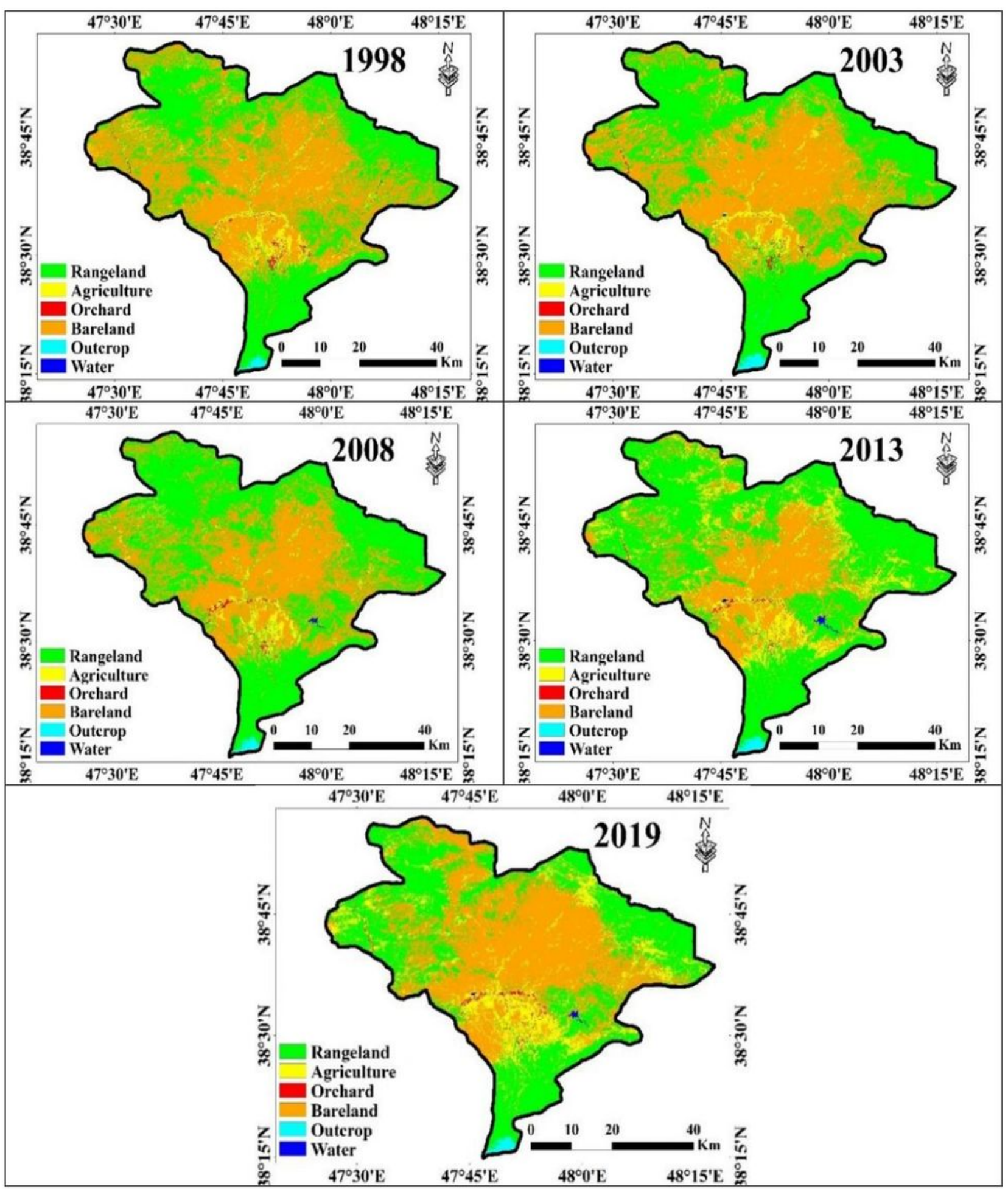

Figure 2

The land use map of East Meshgin area in different years of the given time period Note: The designations employed and the presentation of the material on this map do not imply the expression of any opinion whatsoever on the part of Research Square concerning the legal status of any country, territory, city or area or of its authorities, or concerning the delimitation of its frontiers or boundaries. This map has been provided by the authors. 


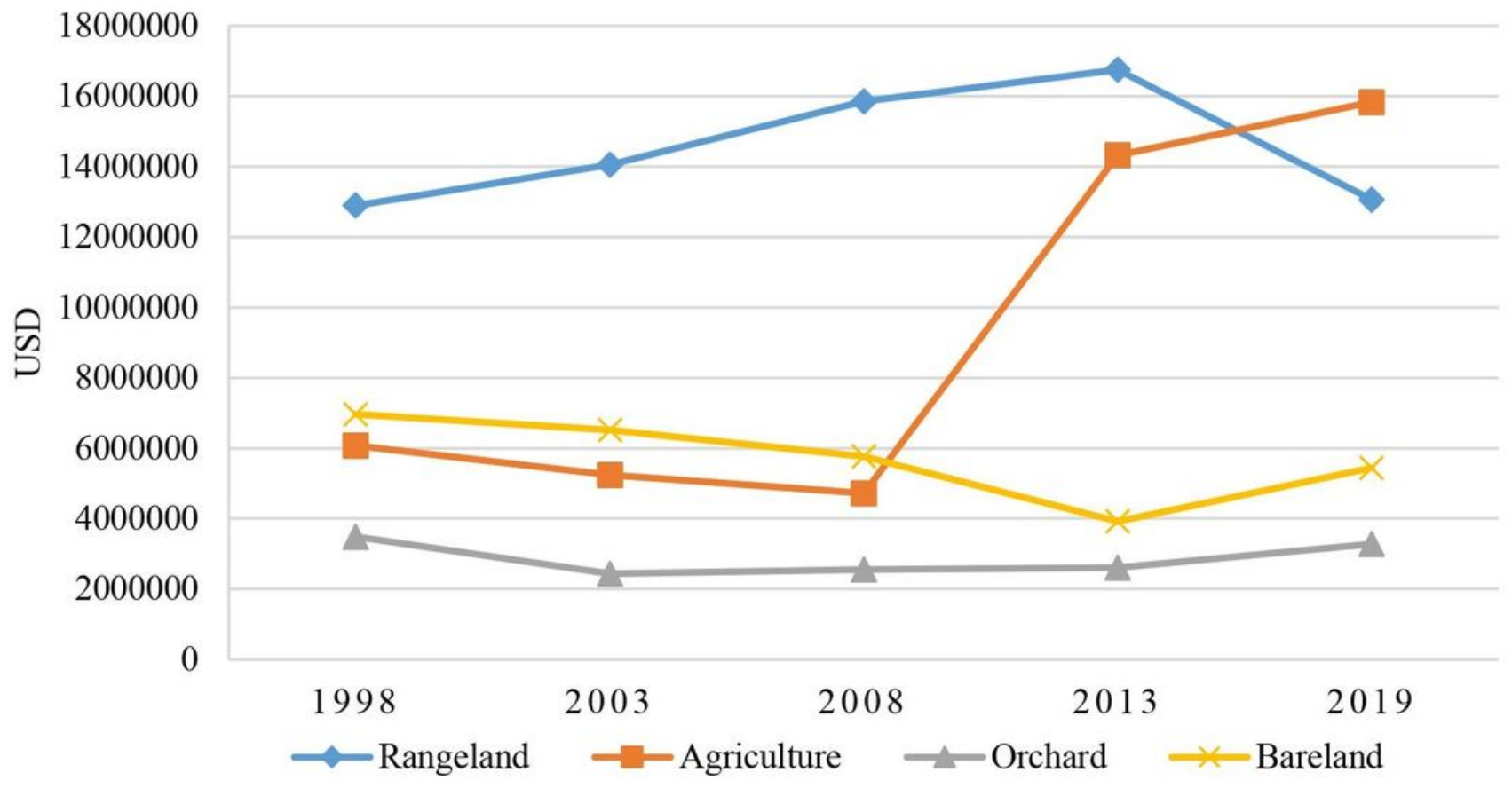

Figure 3

Changes in net income of the main land uses in the studied years of the period under study 


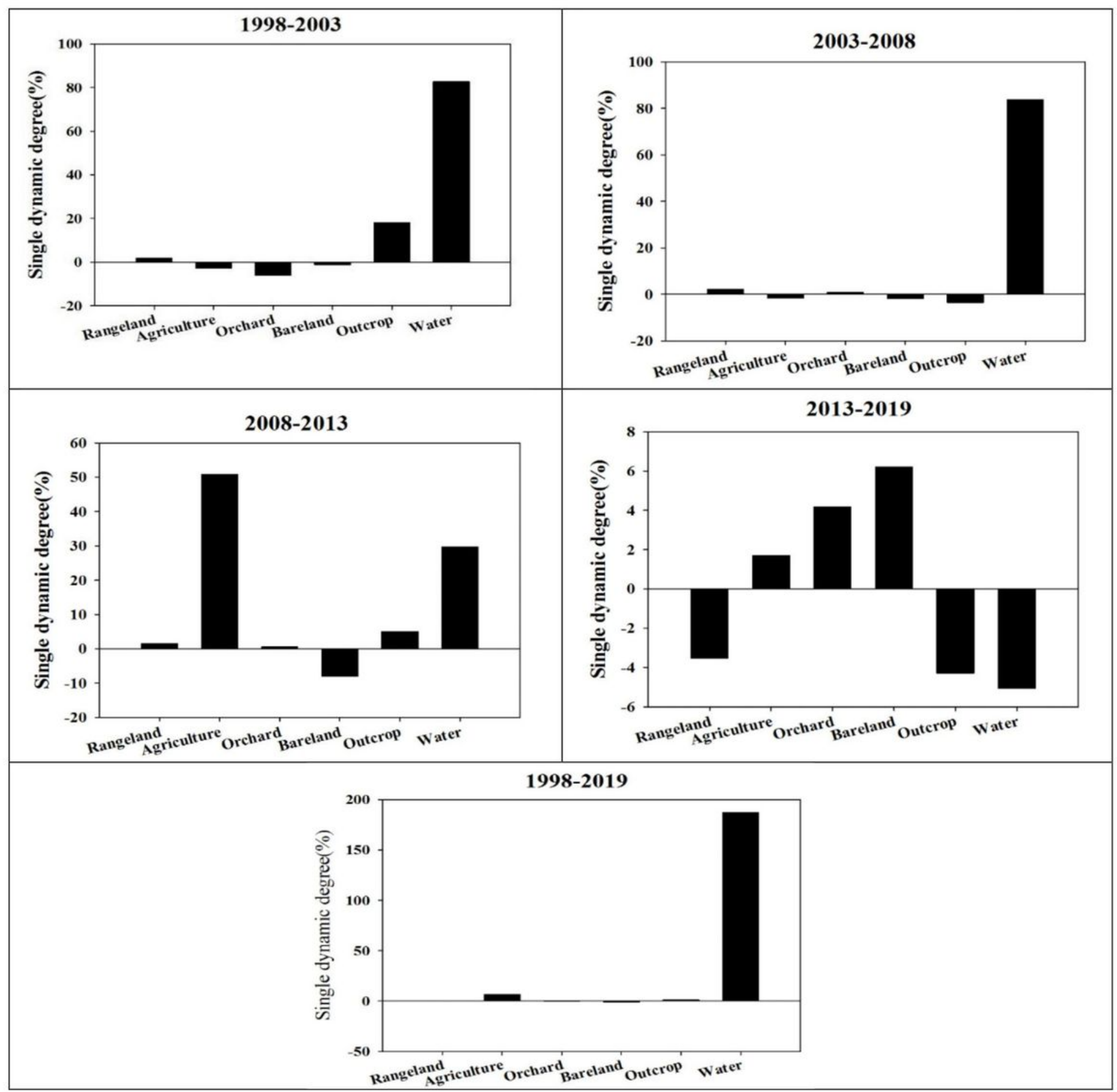

Figure 4

Degree of dynamics of individual land-use change in the East Meshgin area 


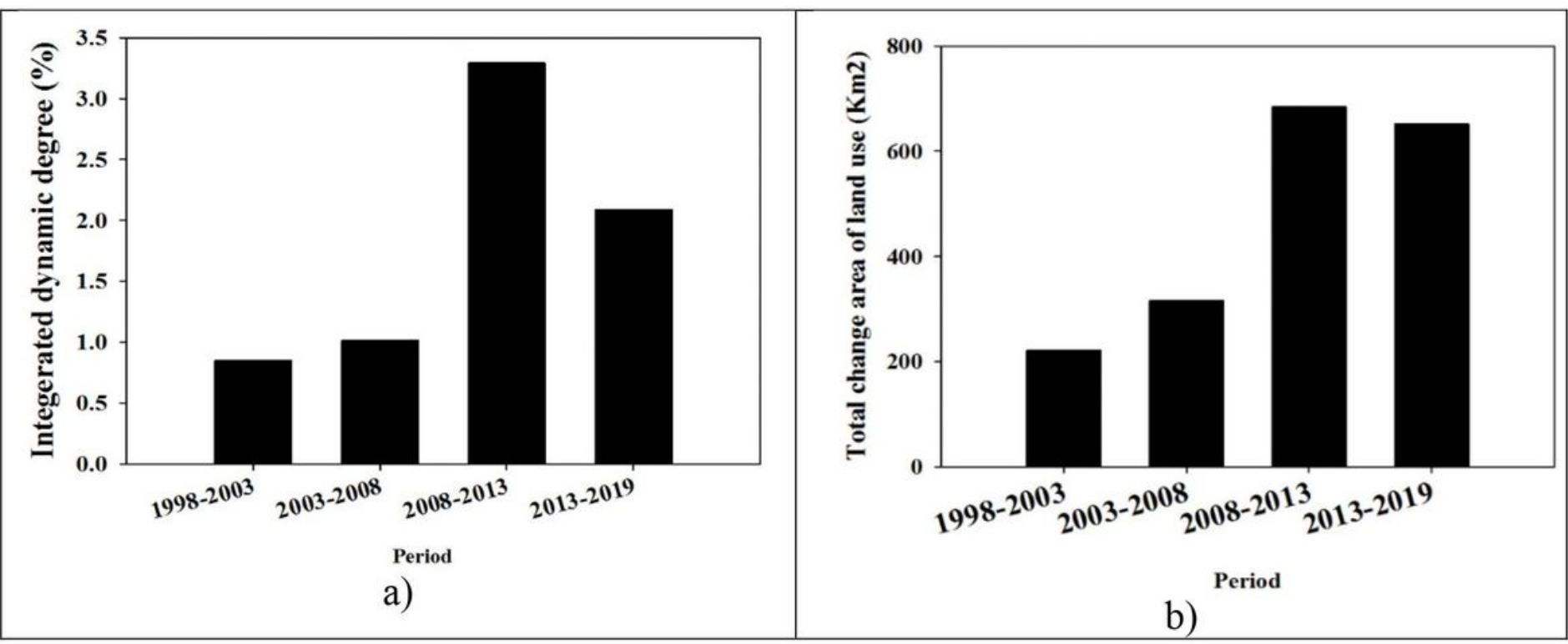

Figure 5

Degree of comprehensive land-use change $(A)$ and total land-use change $(B)$ in each period 